International Journal of Chronic Diseases \& Therapy (IJCDT)

ISSN 2572-7613

\title{
Cultural and Spiritual Dimension of Chronic Disease: An Important Concern for Practitioners
}

Wiwanitkit V

Editorial

Professor, Hainan Medical University, China.

*Corresponding Author:

Viroj Wiwanitkit,

Professor, Hainan Medical University, China.

E-mail:wviroj@yahoo.com

Received: September 02, 2015

Published: September 03, 2015

Citation: Wiwanitkit V (2015) Cultural and Spiritual Dimension of Chronic Disease: an Important Concern for Practitioners. Int J Chronic Dis Ther. 1(2e) 1. doi: http://dx.doi.org/10.19070/2572-7613-150002e

Copyright: Wiwanitkit $\mathbf{V}^{\odot} 2015$. This is an open-access article distributed under the terms of the Creative Commons Attribution License, which permits unrestricted use, distribution and reproduction in any medium, provided the original author and source are credited.

In the present day, it is no doubt that chronic diseases become the important part of human illness. Due to the advanced biomedical technology, the management of acute disease has been abruptly improved for years. Nevertheless, the left problem on chronic diseases, which are usually relating to poor environment and behavior, still exits and become a great concern at present. It is no doubt that there are very high rates of several chronic illnesses such as diabetes mellitus reported from any countries around the world. The management of the chronic illness becomes another focus in medicine and public health globally. The new diagnostic and therapeutic tools are available for management of chronic diseases. However, the problem is still prevalent.
Since the chronic illness means lasting for a long time, the patient compliance to the treatment is very important. It will be no use if there is no good compliance from the patients. Of interest, the focus on only physical and biological factors of the patients such as focusing on blood glucose stabilizing in diabetic patients without holistic consideration is usually problematic and result in failure of chronic disease management. As a holistic approach, the cultural and spiritual dimension of chronic disease should not be forgotten [1]. It is no doubt that local culture and belief has a great effect on disease management. In some contexts, if the practitioner does not recognize and modify the treatment according to the culture-spiritual context, the failure can be expected. The need for modification of diabetic control during Rahmadan period for the patients in Muslim community is the best case study [2]. Sometimes, an aberrant presentation of chronic illness can be expected. The culture bound syndrome is the good example [3]. As a notification, the practitioner should concern holistic approach and details and modify their care, as a medical art, to correspond to each patient.

\section{References}

[1]. Lo R, Brown R (1999) Holistic care and spirituality: potential for increasing spiritual dimensions of nursing. Aust J Holist Nurs 6(2): 4-9.

[2]. Hassan A, Meo SA (2014) Diabetes during Ramadan: underestimated, under-investigated, needs more attention. Eur Rev Med Pharmacol Sci 18(22): 3528-3233.

[3]. Perez S, Junod A, Pilard M (2000) Culture-bound syndromes: pertinence as a diagnostic category. Med Trop (Mars) 60(1): 75-82. 